\title{
A Critical Discourse Analysis of Rhetorical Devices Used in Advertisements of Beauty Products in Pakistani Print Media
}

\author{
Muhammad Imran Shah Naima Saher \\ Department of Applied Linguistics, Government College University Faisalabad
}

\begin{abstract}
The primarily focus of advertising is to persuade the customers. In other words advertising aims to capture the attention of customers and convince them to buy the products by using different persuasive techniques. Beauty products are become the fundamental need of every man and women because everyone wants to be look beautiful also wants to have their spouse to be attractive. Rhetorical devices or rhetoric techniques in advertisements play a vital role to persuade viewers. The current study has also focused on rhetorical devices used in the advertisements of beauty products in Pakistani print media. The researcher's aim was to examine the rhetorical devices used by advertisers in order to capture the attention of customers and also to investigate the representation of gender in beauty products advertisements that control the mind of mind and persuade them to purchase the products. For this purpose, the study has used Critical Discourse Analysis as a research tool. The research was qualitative in nature. Data was collected from beauty products advertisements and these advertisements were taken from print media. Print advertisements were collected from 3 Dawn English magazines and 3 Mag English magazines over a period of three months (April to June 2018). By using systematic random sampling the researcher selected twenty four (24) advertisements (twelve of each gender) from total population as a sample. The data was analyzed through Rhetorical Structure Theory proposed by Mann and Thompson (1988). The findings reveal that hyperbole is the most used rhetorical device. Moreover, alliteration and analogy also frequently used in beauty products advertisements. The researcher also observed that the representation of gender in beauty products are more persuasive and tactic. The advertisers used the representation of celebrities in order to motivate the viewers and to sell their products. The study also concluded that the frequently used relations from subject matter relations are: Elaboration and Explanation and from presentational relations are: Motivation and Evidence.
\end{abstract}

Keywords: Rhetorical Devices, Advertisements, Gender analysis, Pakistani print media.

DOI: $10.7176 / J L L L / 53-03$

\section{Introduction}

Advertising Association of UK defined advertising as a mean of communication with the users of the product or service. Advertisements are messages paid for by those who send them and are intended to inform or influence people who receive them. In today's world, advertising uses every possible media to get its message through. It does this via television, print (newspapers, magazines, journals etc.), radio, press, internet, direct selling, hoardings, mailers, contests, sponsorships, posters, clothes, events, colors, sounds, visuals and even people (endorsements). Advertisements interact to the customers through various media such as television, magazines, internet, newspaper and radio. Advertiser selects the medium in order to check that advertisements are able to reach the specific groups. For this purpose, advertiser selects the target group; for instance, if the target is adults then internet would be the best source and if the target in only females then magazines would be the best source, for old age people television and radio would be fine source.

Advertisements are used for different products for instance, beauty products, car advertisements, cooking oil products, advertisements for food etc. but this study only focused on beauty products advertisements. There are many advertisements in women's magazines that advertise beauty products influencing women and beauty has become an absolute religious imperative for women, thus persuading them to do their to hold their beauty (Baudrillard, 2005). Advertisers used different types of strategies and techniques to manipulate the viewers specially to persuade females to purchase the product. In order to control the minds of people advertisers used different rhetorical devices and the representation of male and female also plays an important role to persuade the customer.

\section{1: Operational Definitions}

Operational definitions of key terms are as follows:

1.1.1: Rhetorical Devices:

A rhetorical device is a linguistic tool that employs a particular type of sentence structure, sound, or pattern of meaning in order to invoke a particular reaction from an audience. According to Kenney and Scott (2003), "traditionally, rhetoric was considered "the exclusive province of verbal language". There are a lot of rhetorical devices, for instance, Logos, Pathos, Analogy, Hypophora, Hyperbole, Anaphora, Kairos, Alliteration etc. but this only focused on Alliteration, Analogy, Anaphora, Hyperbole, Parallelism and Simile. 


\subsection{2: Beauty Concept:}

Kumar (2002) defined beauty as a property associated with human beings, this could be considered even as a characteristic. Kumar said that beauty is used to express nice looking women as opposed to hand-some for men.

\subsection{3: What is Advertisement?}

According to Frank Presbrey, "Advertising is a printed, written, oral and illustrated art of selling. Its objective is to encourage sales of the advertiser's products and to create in the mind of people, individually or collectively, an impression in favor of the advertiser's interest." American Marketing Association defined it as advertising means any paid form of non-personal presentation and promotion of ideas, goods, or services by an identified sponsor.

\subsection{4: Critical Discourse Analysis:}

Critical discourse analysis (CDA) is a type of discourse analytical research that primarily studies the way social power abuse, dominance, and inequality are enacted, reproduced, and resisted by text and talk in the social and political context. According to Ven Dijk, "CDA is a type of discourse analytical research that primarily studies the way power abuse, dominance and inequality are enacted, reproduced, and resisted by text and talk in social and political context".

\subsection{5: Rhetorical Structure Theory:}

Rhetorical structure Theory proposed by Mann and Thomson (1988), "A linguistic theory of how text hangs together". Taboada and Mann (2005) defined RST, "Rhetorical Structure Thoery can be defined as a theory of text organization that has led to areas of discourse analysis and text generation. Mann and Thompson proposed a set of relations, for instance, subject matter relations (informational), presentational relations (intentional) and multinuclear relation. There are two other relations: Nucleus and Satellites.

Subject Matter Relations: Those whose intended effect is that the hearer recognizes the relation in question. They relate to content of the text spans.

Presentational Relations: Those whose intended effect is to increase some inclination in the hearer; such as the desire to act or the degree of positive regard for, belief in, or acceptance of the nucleus. These relations are more rhetorical in nature. They are meant to achieve some effect on the reader.

\section{2: Purpose of the study:}

The purpose of the current study is to examine the role of gender representation and rhetorical devices. It seeks to find the role of rhetoric devices and their use in beauty products advertisements. It also discusses why the representation of gender is necessary to sell the products or to persuade viewers.

\section{3: Objectives of researcher:}

1. To investigate the representation of genders that are used in beauty products' advertisements in Pakistani English magazines for selling different products.

2. To examine the rhetoric techniques that is employed in the beauty products' advertisements in Pakistani English Magazine for persuading customers to purchase the products.

\section{4: Research Questions:}

1. What type of rhetoric techniques are used in beauty products' advertisements in Pakistan to attract customers?

2. How male and female genders are represented in beauty products advertisements in Pakistani English magazines?

\section{5: Significance of study:}

The people of Pakistan are not much aware and easily convinced by media. The advertisers take advantage of this and make advertisements to persuade people through different rhetoric techniques and through representation of gender. This research makes the people aware of the manipulating language of advertisements.

\section{Literature Review:}

In the field of linguistics, the term "Rhetorical Devices" defined by many authors, some defined it as, "traditionally, rhetoric was considered 'the exclusive province of verbal language' (Kenney and Scott, 2003, p19) where presentation of an argument was manipulated so as to be most impacting." (Bulmer \& Oliver, 2006, p.55). Corbett (1990) also defined it as is an artful deviation. According to McQuarrie and Mick (1996) "rhetorical devices occur when an expression deviates from expectations. According to Huang (1999), and Lin (1978), "The basic concept of rhetoric as concerning the art of showing aesthetics".

Another term "Advertisements" has also used in this study. Cook (1992) states that advertisements can amuse, inform, misinform, worry or warn. Some defined it as "advertisement is a message to promote or sell a product" (see Petly, 2002; Arens, 2002). According to Petly (2003) "Advertising is the means by which goods or services are promoted to the public". There are different types of advertisements for instance print 
advertisements, broadcast advertisements, outdoor advertisements, public service advertisements etc. but this study has only focused on print advertisements (magazines).

Linguistics features are interests of the researcher on which they conduct their research. In this study, the linguistic feature "Rhetorical Devices" was researched by Vu Xuan Doan (2017), Gerson Siando (2014), Margot Van Malkon (2003), Hsin Chi Ku (2015), Fatma Naz Koksal (2013). This study has also worked on Rhetorical Devices presented in the beauty products advertisements in Pakistani English Magazines. There are a lot of types of rhetorical devices for instance Logos, Ethos, Pathos, Alliteration, Anaphora, Hyperbole, Hypophora etc. but this study has only interested in explore Alliteration, Analogy, Anaphora, Hyperbole, Parallelism and Simile.

According to $\mathrm{Vu}$ Xuan Doan (2017), the researcher worked on rhetoric in television advertising in Vietnam. The researcher used quantitative approach to find the frequencies of rhetoric in advertising. For this purpose the researcher selected 200 videos of television advertising, including 123 short advertisements for 15 seconds, 74 advertisements for 30-40 seconds; 1 very short advertisement with 7 seconds; an advertisement that is longer than 1 minute and a special advertisement of 2 minutes. These advertisements relate to many types of products and to all consumers. All rhetorical figures in the form of images, words, and sounds are noted. The results showed that repetition, hyperbole, and comparison (including metaphor) were used the most, accounting for $99 \%$, $73 \%$ and $70 \%$, respectively. Other methods have much lower frequency of less than or equal to $32 \%$. The study also concluded that rhetorical figures are used frequently to influence the emotions of consumers.

According to Gerson Sindano (2014), the researcher worked on "A Study of Rhetorical Devices Used in Selected Cars Advertisements in The Namibian Newspaper". The researcher conducted qualitative researcher in order to examine the language used in car advertisements and to explore the rhetorical strategies. For this purpose, the researcher collected forty car advertisements from The Namibian newspaper. The researcher used persuasive moves suggested by Hashim (2010). The finding contains new moves that are not part of what Hashim suggested. The results showed that car advertisements contain slogans, aggressive language, comparative and superlative form. At the end the researcher gave recommendations for further study or researcher that further study be undertaken into car advertisements to explore rhetorical strategies unique to Namibian.

According to Margot Van Malkon (2003), the researcher worked on “Analyzing Rhetorical Devices In Print Advertisements". For this study the researcher used both qualitative and quantitative approaches in order to test the feasibility of the two taxonomies. For this purpose, data was collected from 1000 French and Dutch magazine advertisements. The researcher practiced two framework as a model, first one was Text-Interpretive Analysis devised by McQuarrie and Mick $(1996,1999)$ and the other was Visual Rhetoric approach by Groupe $\mathrm{Mu}$ (1992). The results show that neither framework is completely infallible, and that both frameworks present inadequacies with regard to their feasibility. The model proposed in McQuarrie and Mick 1996 appears, however, to be the most promising. The study also concluded that the application of taxonomy is not unequivocal of both frameworks.

According to Dr. Faraz Ali Bughio (2015), the researcher worked on the representation of men and women in advertisements aired on Pakistani T.V channels and internet (Western). The researcher used Critical Discourse analysis and semiotics as a research tool to analyze social values, choices, ideologies that are produced through advertisements. The study also focused on gender inequality and power relations. The data was based on twelve advertisements aired on Pakistani T.V channels and internet. The study was based on qualitative approach. The researcher used Fairclough's three dimensional framework description, interpretation and explanation as a model. Another model "propaganda model" proposed by Herman and Chomsky also used to problematize ads. The results showed that advertisements promote gender inequality and the patriarchal ideology. Women represented as soft, ignorant but intellectual and men represented as courageous, bold. The study also concluded that advertisements serve social power relation and support the patriarchal state.

According to Kuldip Kaur (2013), the researcher worked on beauty product advertisements in local English magazines. In this study Critical Discourse Analysis used as a research tool to examine the use of language in advertisements and explore the strategies to manipulate customers. For this purpose, data was collected from two popular local women's magazines, Cleo and Women's Weekly. The research was qualitative in nature. The researcher used Fairclough's three dimensional frameworks: textual, discursive practice and social practice as a research tool. The results showed that advertisers used different strategies to persuade women and promote an idealized lifestyle. This study also showed that how the ideology of beauty is constructed and reconstructed through magazines. The study concluded that the language of advertisements used to control people's mind through power (advertiser).

According to Shehbaz Ali and Deeba Shahwar (2011), the researcher worked on the representation of men and women in the advertisements of Pakistani Electronic Media. Content Analysis method was used to explore the trends of female portrayals in advertisements. Quantitative based approach was used for this study. The researchers collected one hundred and fifty commercials ads aired over Pakistani T.V channels between $1^{\text {st }}$ July 2008 to $31^{\text {st }}$ December 2008. Commercials were grouped into 9 different categories. The findings reveal that the 
number of female characters is higher than male characters. The study also showed that most of the females are shown engaged in domestic tasks. Moreover, content analysis also revealed that stereotypical approaches were followed. The study also concluded that women are being portrayed in limited roles and most of the portrayal was against the culture and social values.

\section{Methodology:}

The researcher employed qualitative research in order to study the rhetorical devices used in beauty products' advertisements. For this purpose the researcher selected two magazines i.e. Dawn and The Mag (3 magazines of each) to investigate the representation of gender in beauty products' advertisements. The researcher's aim is to study the rhetorical techniques that are used in beauty products advertisements to persuade the viewers to buy the products. For this aim the researcher used Rhetorical Structure Theory by Mann and Thompson (1988) as a research tool.

\section{1: Theoretical Framework:}

This study adopts Rhetorical Structure Theory by Mann and Thompson (1988) to analyze the data. The analysis focused on how the representation of gender and use of rhetorical devices in the advertisements persuade consumers. According to Mann and Taboda (2005), "Rhetorical Structure Theory can be defined as a theory of text organization that has led to areas of discourse analysis and text generation". Mann and Thompson defined RST as "A linguistic theory of how text hangs together". Mann and Thompson proposed a set of relations, for instance, subject matter relations (informational), presentational relations (intentional) and multinuclear relation. There are two other relations: Nucleus and Satellites.

Subject Matter Relations: Those whose intended effect is that the hearer recognizes the relation in question. They relate to content of the text spans.

Presentational Relations: Those whose intended effect is to increase some inclination in the hearer; such as the desire to act or the degree of positive regard for, belief in, or acceptance of the nucleus. These relations are more rhetorical in nature. They are meant to achieve some effect on the reader.

\section{2: Population and Sampling:}

Data was collected from beauty products advertisements and these advertisements were taken from print media. Print advertisements were collected from 3 Dawn English magazines and 3 Mag English magazines over a period of three months (April to June 2018). From total population 24 beauty products advertisements (12 of each gender) were selected as a sample to see the representation of male and female and to study the rhetorical devices. The researcher used systematic random sampling. Advertisements that were selected for female products were related to beauty creams, soaps and facewashes, cosmetics and lotions while for males' advertisements were about beauty creams, facewash, shaving gel and razor, perfumes and shampoos.

\section{3: Research Instrument:}

For this research, data was collected from print advertisements. The researcher used digital camera as an instrument to collect data from magazines. Pictures of beauty products' advertisements were taken from magazines with 8 mega pixel digital camera.

\section{4: Data collection procedure:}

Data was collected only in one way- from Pakistani print advertisements. The time period of data collection was from April 2018 to June 2018. Print advertisements were collected from 3 Dawn English magazines and 3 Mag English magazines. The researcher purchased these magazines from bazar. Through systematic random sampling 24 advertisements of beauty products (12 of each gender) selected from all these magazines. Advertisements that were selected for female products were related to beauty creams, soaps, cosmetics and lotions while for males' advertisements were about beauty creams, facewash, shaving gel and razor, perfumes and shampoos.

\section{Data Analysis:}

After the data collection procedure, the researcher analyzed data in two phases. In first phase data related to female beauty products advertisements were analyzed and in second phase data related to male beauty products advertisements were analyzed. In both phases analysis based on two steps, in first step data was analyzed by using framework of Mann and Thompson "Rhetorical Structure Theory" in order to find the rhetorical devices used to persuade people and in second step the researcher investigate the representation of gender, "why these representations are necessary to sell the products", without using any model or framework.

\section{1: Analysis of female beauty products advertisements:}

Advertisements that were selected for female products were related to beauty creams, soaps and facewashes, 
cosmetics, and lotions. The researcher first analyzed rhetorical devices by using Rhetorical Structure theory.

Subject matter relations:

Subject matter relations are those whose intended effect is that the hearer recognizes the relation in question. Some advertisements related to beauty creams are given below.

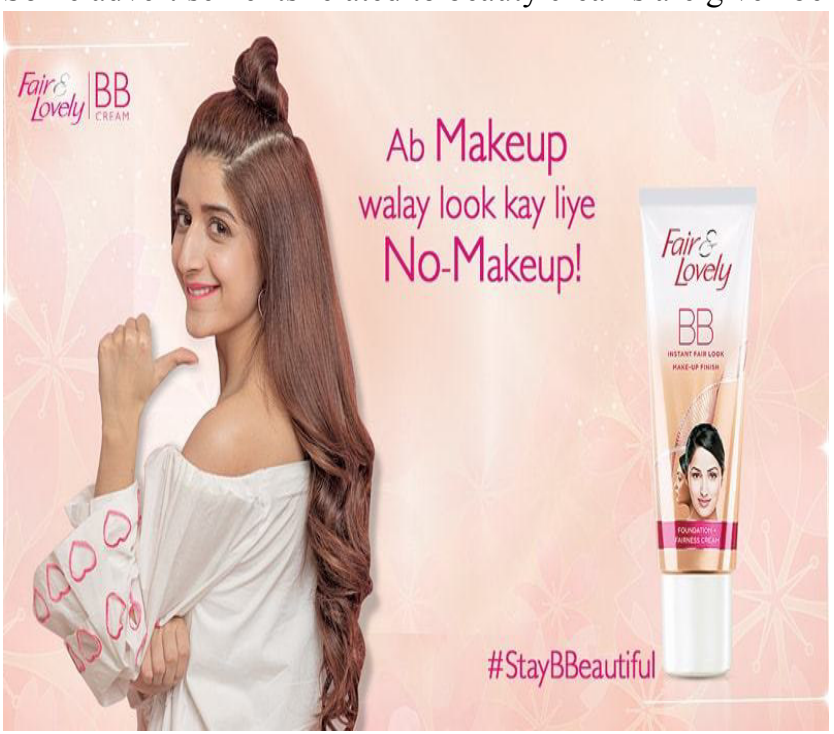

Figure 1a

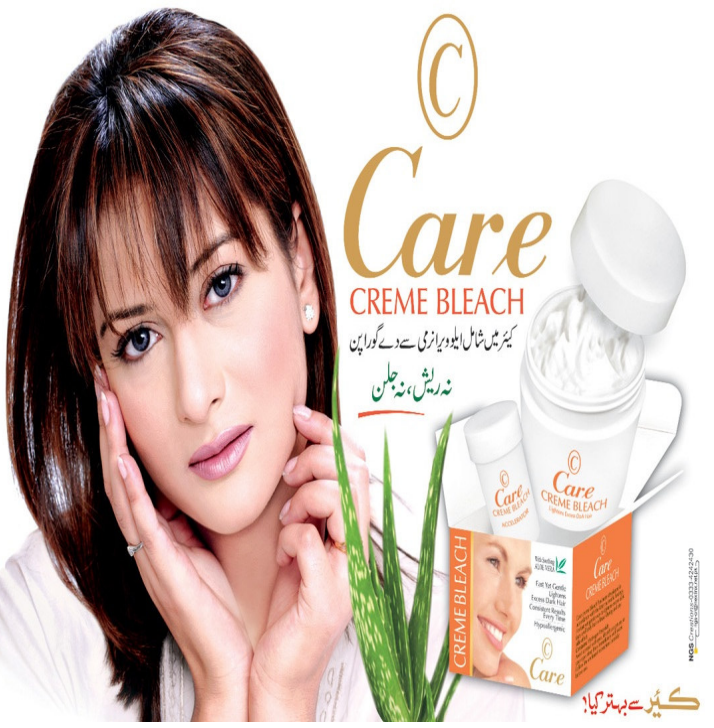

Figure $1 \mathrm{~b}$

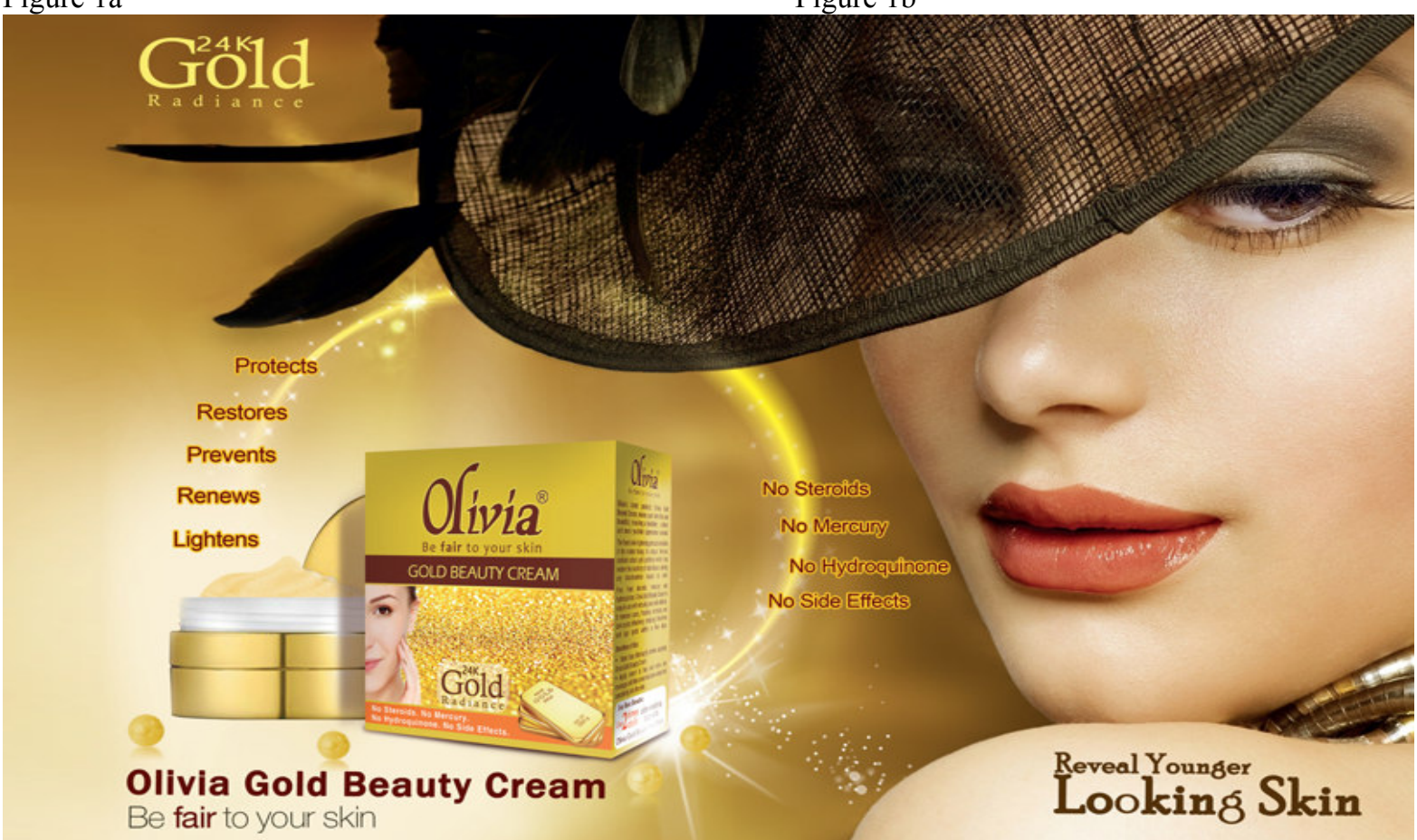

Figure 1c

In figure $1 \mathrm{a}$, the advertisement is related to BB cream for females. The slogan of the product is "Ab makeup waly look ky liye no makeup", it effects on the minds of the viewers that only a cream is enough instead of whole makeup. In this advertisements "Solution hood relation" is used in which the problem is makeup wala look and the solution is no makeup. The advertiser used "hyperbole" in order to persuade the consumers for purchasing the product.

In figure $1 \mathrm{~b}$, the advertiser used "Logos" as a rhetoric strategy to persuade the readers by giving them logic that there is no harm in using this cream "na raish na jalan". A rhetorical question is also used in this advertisement "Care sy behtar kya"? There is no clear any subject matter relation in this ad.

In figure 1c, Elaborations and Explanation are used to present the advantages of this product. "Reveal Younger Looking Skin" this statement is used to manipulate females because females are age conscious and want to look younger always.

The research observed that the representation of females in advertisements is more persuasive and mind 
controlling.

Advertisers of beauty soaps also used persuasive techniques in order to sell their products. Some advertisements are given below:

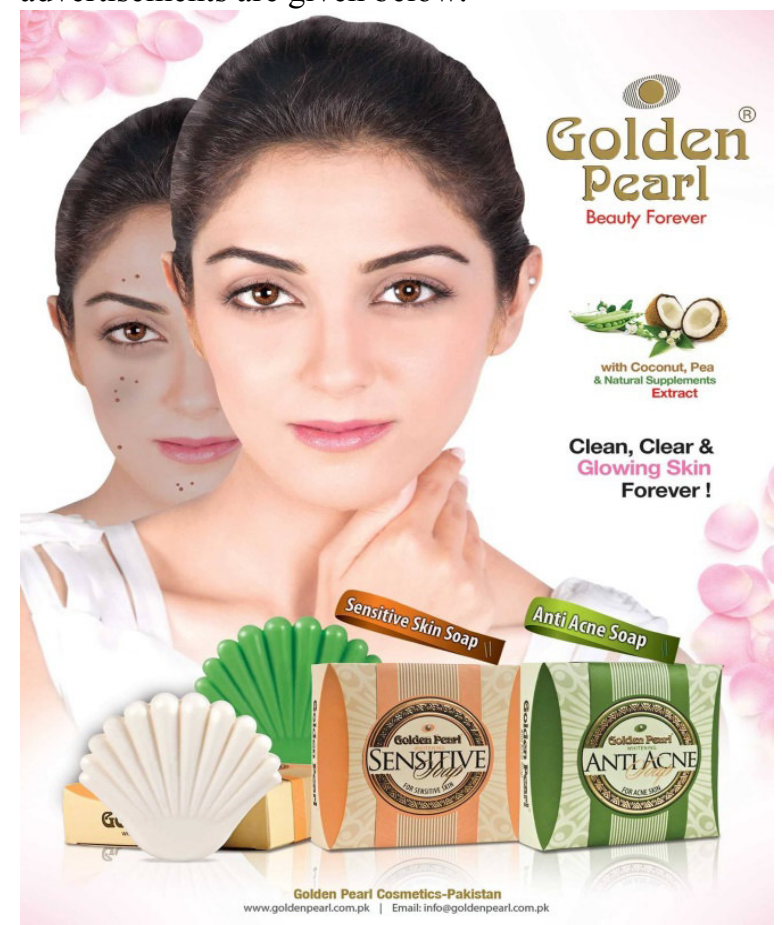

Figure 2a

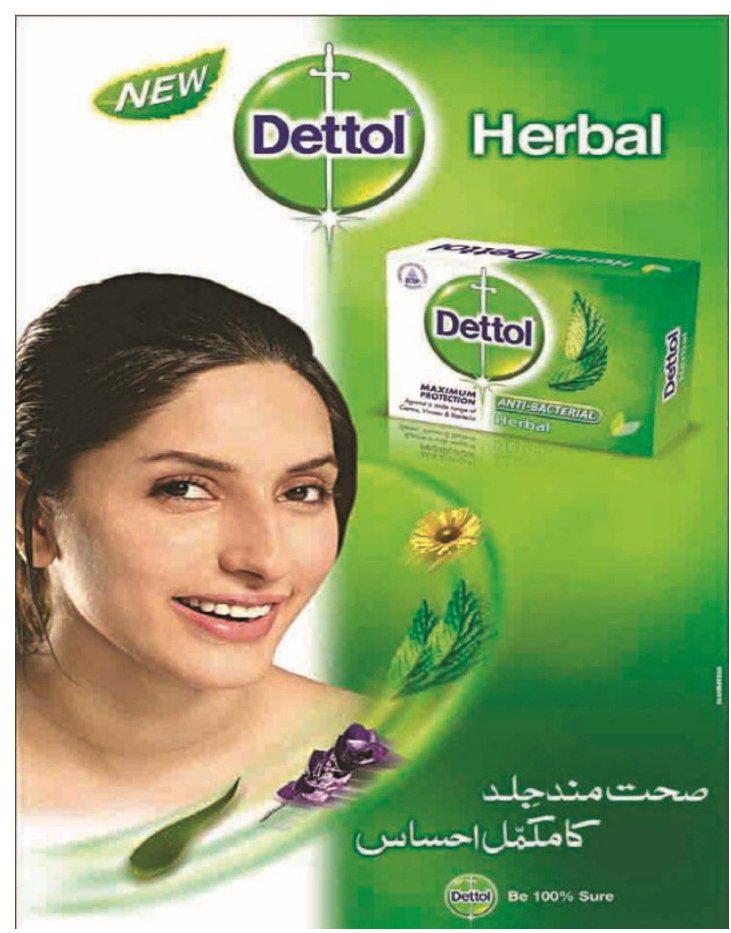

Figure $2 b$

The researcher observed that the use of subject matter relations in advertisements is very less but rhetorical devices used in almost all advertisements in order to persuade the consumers. In figure 2a "Alliteration" is used, for instance, $\underline{\text { Clean, }}$ Clear and Glowing Skin I. The pictures of coconut and pea also catch the attention of viewers and as for as the representation of female is concerned, there are 2 images of female in back image her skin is damaged by pimples but the front image shows that after using soap her skin become clean and clear.

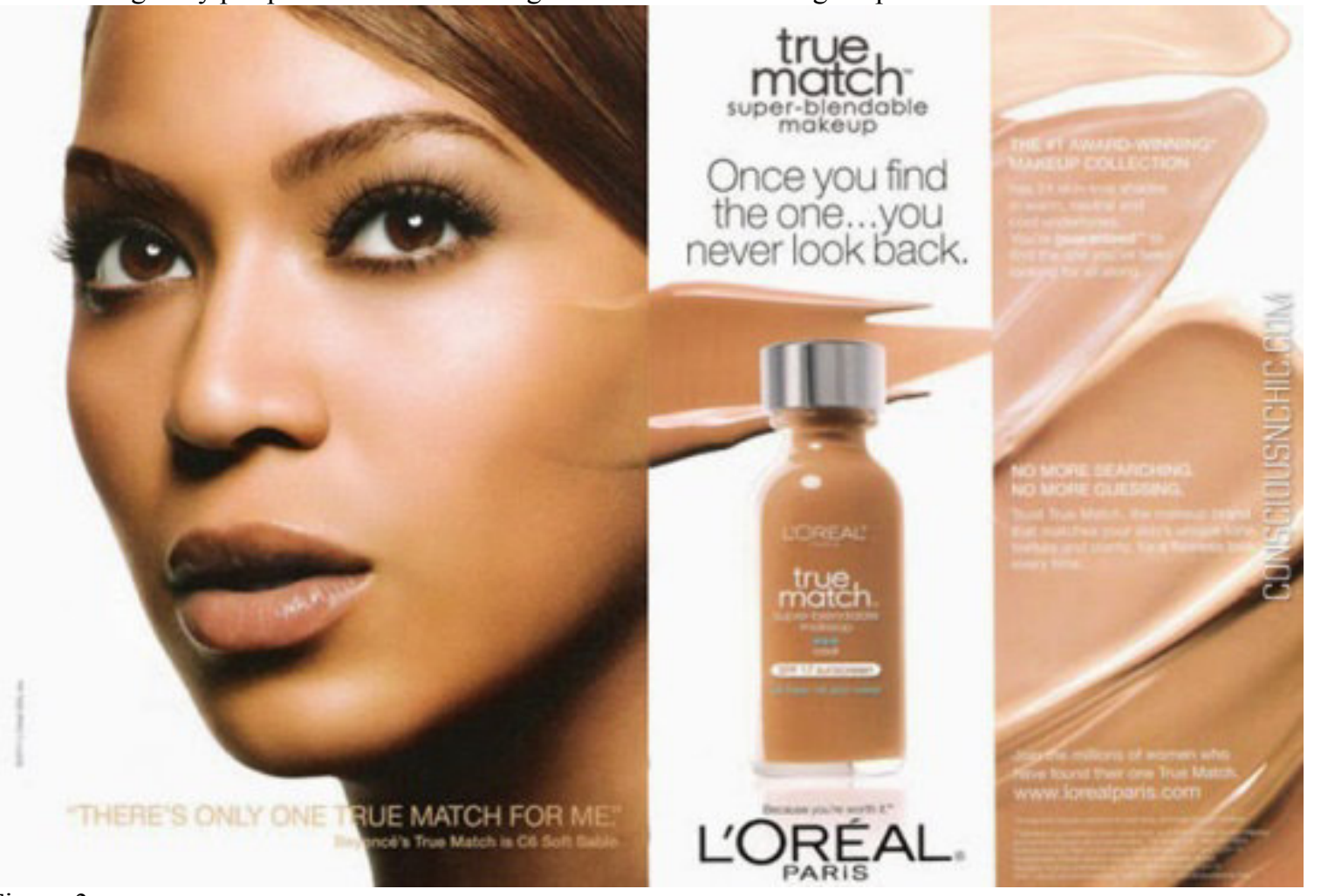

Figure 3

This advertisement (figure 3) is related to cosmetics. Loreal is the very famous cosmetics brand in Pakistan. 
The advertiser used a very tactic slogan to control the minds of people "Once you find the one... you never look back",

Presentational Relations: These types of relations are more rhetorical in nature. The purpose of these relations is to increase some inclination in the hearer.

The researcher observed that presentational relations mostly used in all beauty products advertisements to motivate their consumers for purchasing the product. The representation of gender also play very important role to catch the attention of females, representation of gender in advertisements is also a type of motivation. In above mentioned advertisements, females are represented in all in order to motivate the female customers. It is also observed advertiser used the representation of female even in male products advertisements just to control the minds of people.

The representation of female wearing hijab is more tactic or persuasive and control the mind specially those females who are strict to wear hijab. It also represents our culture and religion. As shown in Figure 4:

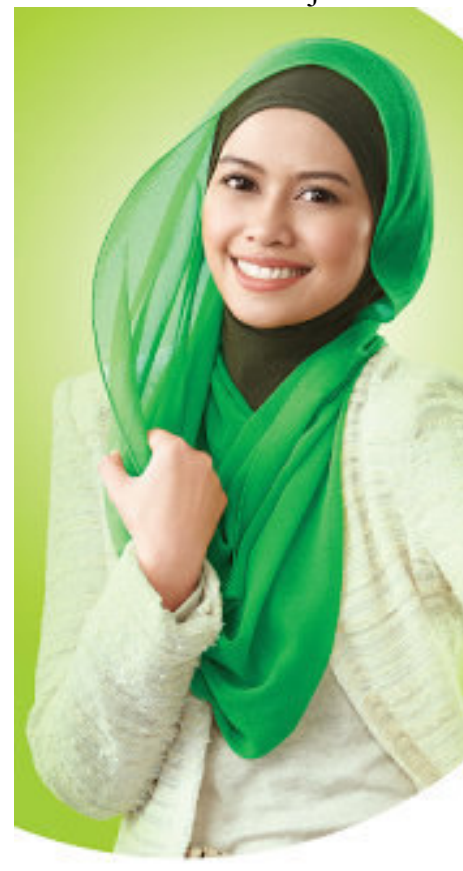

The researcher also observed that advertisers used "Evidence relations" in which first they claim about their product and then give evidence and sometimes their claims and evidences based on exaggeration (hyperbole).

\section{2: Analysis of male beauty products advertisements:}

During the analysis of second phase the researcher observed that the representation of males is very less in male beauty products advertisements in print media as compared to females. But in electronic advertisements males are used almost in all type of advertisements. It is also observed that to catch the attention of males the advertiser presents females in male advertisement and males also represent in females products. 


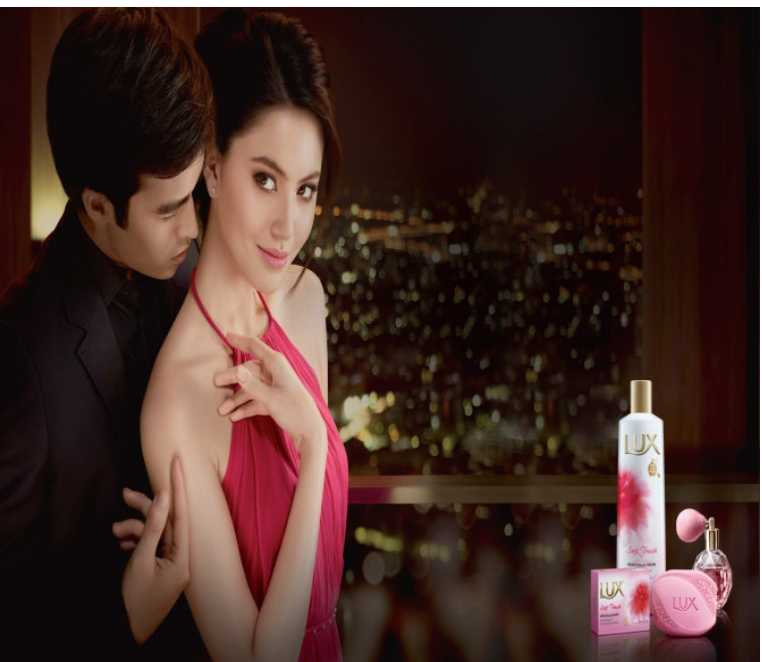

Figure 5a

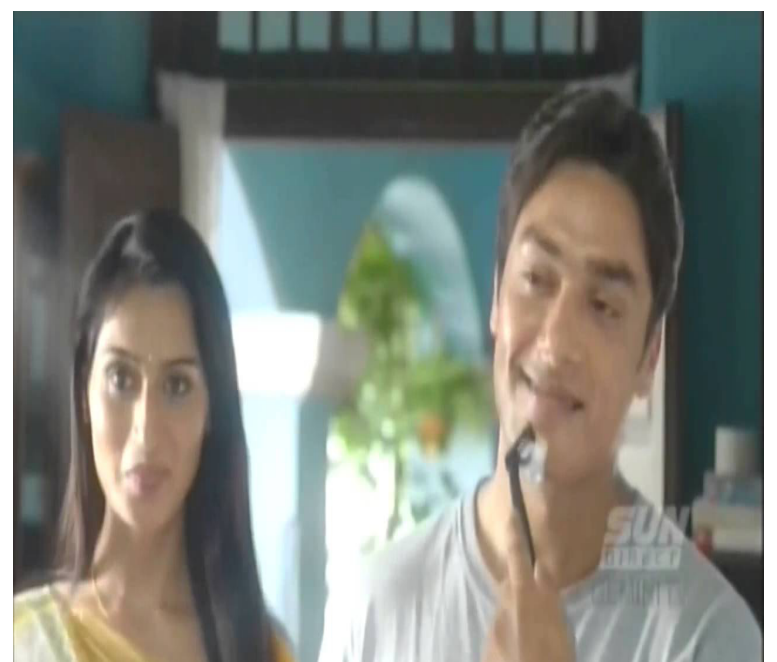

Figure $5 \mathrm{~b}$

Figure $5 \mathrm{a}$ is the advertisement of female soap in which male is represented. Although there is no any rhetorical device or relations are present buy the representation of gender is used as a rhetoric technique. Same as in figure $5 b$, the advertisement is related to male razor but female is represented in order to attract people.

The representation of celebrities also plays a vital role in order to catch the attention of people. In males beauty products advertiser used mostly the representation of celebrities.

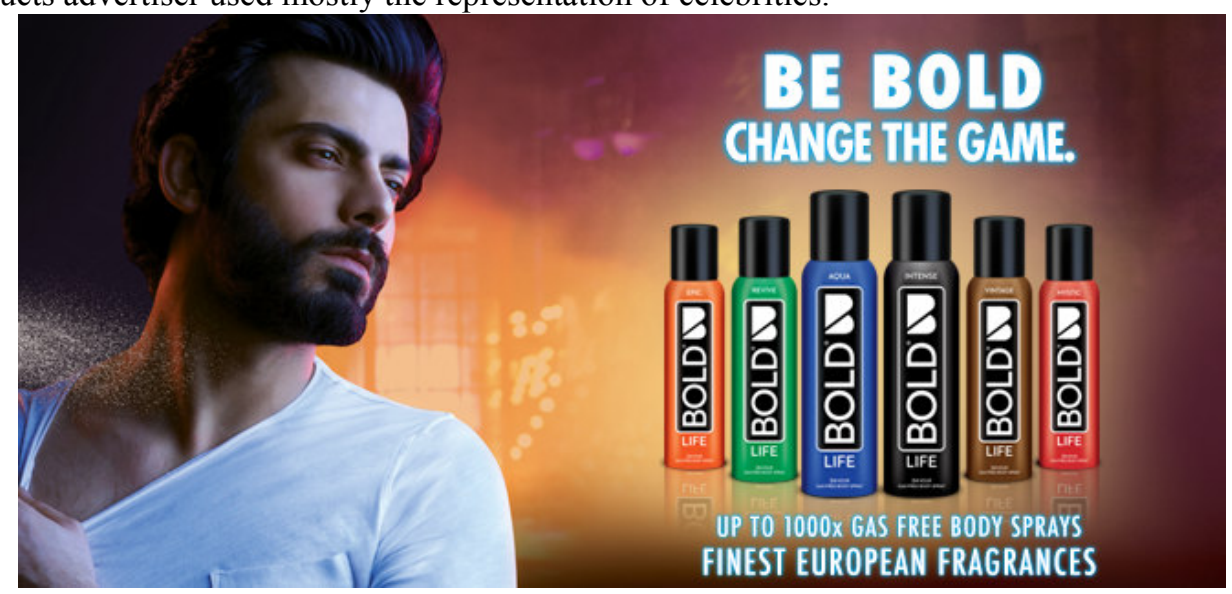

Figure 6

Fawad Khan a very famous actor of Pakistan represented in the advertisement of perfume. Advertiser used these representations to motivate the people because many people consider them their ideal and want to be like them that's why these representation are more persuasive and rhetoric. Alliteration is also used in slogan " $\underline{B} e$ Bold". The research found that this advertisement based on presentational relations.

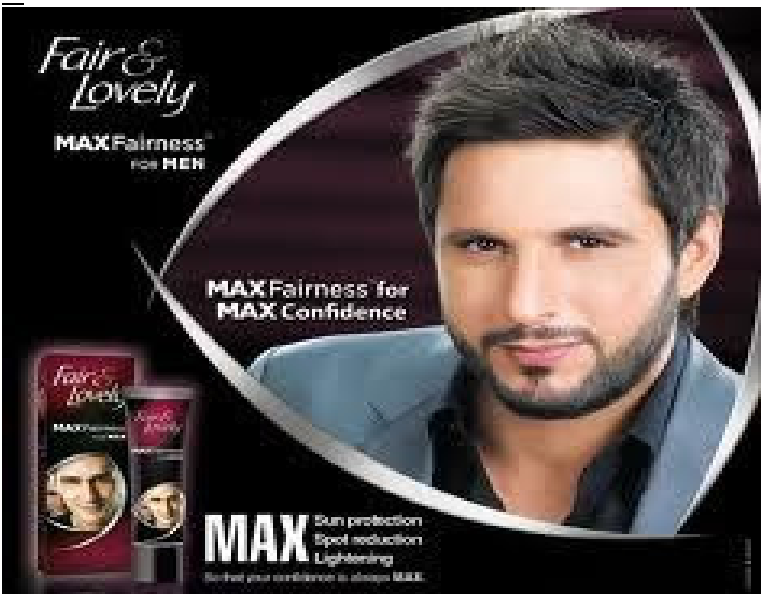

Figure $7 \mathrm{a}$

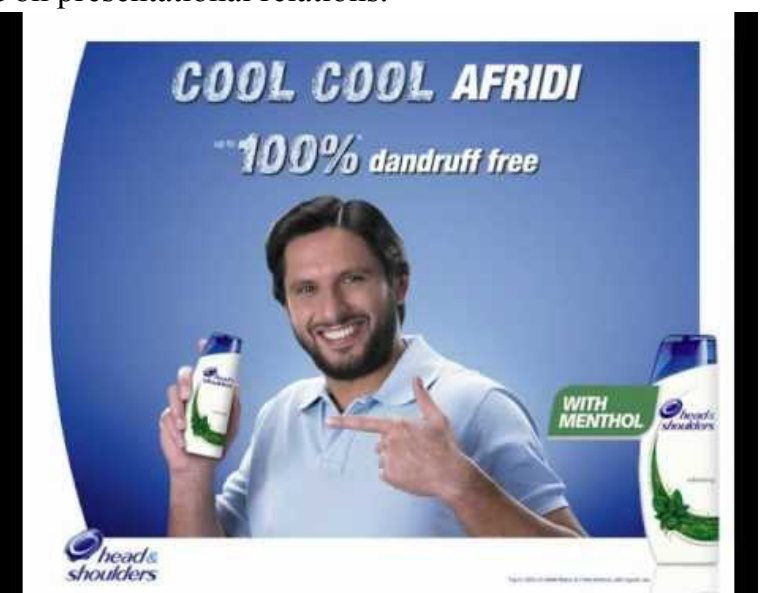

Figure $7 \mathrm{~b}$

Shahid Afridi as a cricketer is the ideal of many youngsters and his representation in advertisements plays 
very tactic role and catch the attention of males. These advertisements related to presentational relations.

\section{Results and Discussion:}

After analyzing the data of beauty products advertisements the researcher observed that the advertiser used different types of persuasive techniques in order to manipulate the male and female. Findings of rhetorical devices relate to the first question "What types of rhetoric techniques are used in beauty products" advertisements in Pakistani print media to attract customers"? The researcher found that advertisers used different types of rhetorical devices to attract people and to sell their products. There are a lot of rhetorical devices but this study only focused on Alliteration, Analogy, Anaphora, Hyperbole, Parallelism and Simile. The findings reveal that hyperbole is the most used rhetorical device. Moreover, alliteration and analogy also frequently used in beauty products advertisements.

The researcher also investigated the representation of gender which relates to the second research question "How male and female genders are represented in beauty products advertisements in Pakistani English magazines?" The results showed that the representation of gender is more tactic than any rhetorical device. Especially the representation of females in all advertisements whether it relates to males' products or females' products considered very essential to sell the products. The researcher observed one thing more that through the representation of gender advertiser tried to show the culture of Pakistan and used eye catching effects in order to control the mind of people. Moreover, the representation of celebrities in advertisements is very persuasive and tactic. The advertisers prefer to take Pakistani actor or actresses in advertisements to catch the attention of consumers because their representation motivates the people. Many people want to be like them and copy their style that's why their representation plays a very tactic role to manipulate the consumers and persuade them for purchasing the product.

\subsection{Conclusion}

The current study mainly focused on rhetorical devices used in the beauty products advertisements in Pakistani print media and on the representation of gender. The results of the study confirm the presence of rhetorical devices in the advertisements of beauty products. The results have showed that rhetorical devices are used to influence the emotions of people. The most used rhetorical figures in beauty products advertisements are hyperbole, alliteration and analogy. The findings also reveal that representation of celebrities plays very important role to manipulate people specially to persuade females. The ideology of power is portrayed by celebrities in the beauty products advertisements. Every woman wants to look attractive as reflected in the images of magazines. The representation of gender is more persuasive than any rhetorical device. Moreover, the language used in advertisements also played tactic role to control the mind of public. Language is the most powerful source of communication. People use language to communicate. Just like other media, magazines portray a great influence on people. In short, advertiser used different rhetoric techniques in order to manipulate the male and female.

\section{References:}

Ali, S., \& Shahwar, D. (2011). Men, women and TV Ads: The representation of men and women in the advertisements of Pakistani electronic media. Journal of media and communication studies, 3(4), 151-159.

Arens, W. F. (2002). Contemporary Advertising (10th ed.). New Delhi: McGraw- Hill.

Baudrillard, J. (2005). The finest consumer object: The body. In M. Fraser, \& M. Greco (Eds.), The Body: A Reader (pp. 277-282). London and New York: Routledge.

Bulmer, S. \& Oliver, M. B. (2006). Visual rhetoric and global advertising imagery, Journal of Marketing Communications, 12(1), 49-61.

Cook, G. (1992). The Discourse of Advertising, London.

Corbett, E.P.J. Classical Rhetoric for the Modern Student. New York: Oxford University Press. 1990.

Huang. L. J. (1999). Practical rhetoric. Taipei: Kuo Chia Publishing.

Kaur, K., Arumugam, N., \& Yunus, N. M. (2013). Beauty product advertisements: A critical discourse analysis. Asian Social Science, 9(3), 61.

Kumar, P. (2002). Concept of Beauty in India: International Journal of Cosmetic Surgery and Aesthetic Dermatology, Vol.4, pp. 261-264.

Lin, Y. S. (1978). Practical rhetoric. Taipei: Way to Win.

Mann, W. \& Thompson, S. A. (1987). Rhetorical Structure theory: A theory of text organization. Marina del Rey, CA: USC Information Sciences Institute.

Mann, W. \& Taboada, M. (2005). An introduction to Rhetorical Structure eory (RST). http:// www.sil.org/ mannb/rst/rintro099.htm (accessed 21 February 2005).

McQuarrie, E.F., and D.J. Mick. "Figures of Rhetoric in Advertising Language. Journal of Consumer Research 24, 4 (1996):424-38. 
Peng, G. (2009). Using Rhetorical Structure Theory (RST) to describe the development of coherence in interpreting trainees. Interpreting, 11(2), 216-243.

Petley, J. (2002). Advertising. London: Great Britain.

Rosul, S. (2011). A Critical Discourse Analysis of Fairness-Product Advertisements for Women and Men (Doctoral dissertation, East West University).

Sindano, G. (2014). A study of rhetorical devices used in selected car advertisements in the Namibian newspaper(Doctoral dissertation).

Shaikh, M., Bughio, F. A., \& Kadri, S. A. (2015). THE REPRESENTATION OF MEN AND WOMEN IN ADVERTISEMENTS: A CRITICAL DISCOURSE ANALYSIS. Women (1997-2032), 7.

Van Dijk, T. A. (2001). Critical Discourse Analysis. In Tannen, D., Cliffrei, D. And Hamilton, H. (Eds), The Hand Book of Discourse Analysis. pp. 353-371.

Van Mulken, M. (2003). Analyzing rhetorical devices in print advertisements. Document design, 4(2), 114-128. 